\title{
Adapting the IUCN Red List criteria for invertebrates
}

\author{
Pedro Cardoso ${ }^{\mathrm{a}, \mathrm{b}, *}$, Paulo A.V. Borges ${ }^{\mathrm{b}}$, Kostas A. Triantis ${ }^{\mathrm{b}, \mathrm{c}}$, Miguel A. Ferrández ${ }^{\mathrm{d}}$, José L. Martín ${ }^{\mathrm{e}}$ \\ a Smithsonian Institution, National Museum of Natural History, Washington, DC, USA \\ ${ }^{\mathrm{b}}$ Azorean Biodiversity Group (CITA-A), University of the Azores, Angra do Heroísmo, Portugal \\ ${ }^{\mathrm{c}}$ Department of Ecology and Taxonomy, Faculty of Biology, National and Kapodistrian University of Athens, Athens, Greece \\ d Sociedad para el Estudio y la Conservación de las Arañas, Madrid, Spain \\ ${ }^{\mathrm{e}}$ The Canary Agency for Sustainable Development and Climate Change, Santa Cruz de Tenerife, Canary Islands, Spain
}

\section{A R T I C L E I N F O}

\section{Article history:}

Received 16 March 2011

Received in revised form 21 June 2011

Accepted 26 June 2011

Available online 29 July 2011

\section{Keywords:}

Arthropoda

Conservation priority

Extinction

Risk assessment

Threatened species

World Conservation Union

\begin{abstract}
A B S T R A C T
The IUCN Red List is the most useful list of species that are at risk for extinction worldwide, as it relies on a number of objective criteria. Nevertheless, there is a taxonomic bias that excludes species with small body sizes, narrow distribution ranges and low dispersal abilities, which constitute the vast majority of the planet's biota, particularly local endemics.

By evaluating each IUCN criterion separately, we (i) identify the shortcomings for invertebrate applications, (ii) explain how risk categories may be wrongly applied due to inapplicable and/or misleading thresholds, (iii) suggest alternative ways of applying the existing criteria in a more realistic way and (iv) suggest possible new criteria that were not considered in the current evaluation framework but that could allow a more comprehensive and effective assessment of invertebrates.

By adapting the criteria to rely more explicitly on the Area of Occupancy and the Extent of Occurrence, their respective trends and by using ecological modelling methods, the criteria's applicability would be increased. The change in some thresholds or, eventually, the creation of sub-categories would further increase their adequacy. Additionally, co-extinction could be introduced as an explicit part of the classification process.

As a case study, we evaluated 48 species of Azorean arthropods and Iberian spiders according to the current criteria. More than one-quarter (27\%) of all evaluated species were classified as Critically Endangered, $19 \%$ as Endangered, $6 \%$ as Vulnerable and $8 \%$ as Least Concern. The remaining $40 \%$ did not have enough data to reach a classification.
\end{abstract}

(c) 2011 Elsevier Ltd. All rights reserved.

\section{Introduction}

There is an increasing awareness that the vast majority of extinctions go unnoticed because they occur within small, strongly neglected organisms (e.g., Koh et al., 2004; Dunn, 2005; Dunn et al., 2009; Régnier et al., 2009; Cardoso et al., 2010; Triantis et al., 2010). However, for a number of reasons, invertebrates are rarely considered in conservation policies. Worldwide conservation efforts have mostly relied on a few emblematic groups. This is largely driven by substantial confidence in the umbrella species concept. Umbrella species are still widely used by managers and researchers, but this practice is now strongly questioned, and the use of umbrella species has been shown to be largely speculative and unfounded (Muñoz, 2007; Cabeza et al., 2008; Martín et al., 2010). Moreover, some invertebrate groups are, in many cases, the first to become extinct in response to habitat loss and disturbance

\footnotetext{
* Corresponding author at: Azorean Biodiversity Group (CITA-A), Universidade dos Açores, Rua Capitão João d'Ávila, 9700-042 Angra do Heroísmo, Portugal. Tel.: +351295402 200; fax: +351295402205.

E-mail address: pcardoso@ennor.org (P. Cardoso).
}

(Cardoso et al., 2010), and they often are the only endangered animals that live on islands or in caves (Martín et al., 2010). Classifying invertebrates according to their risk level and establishing objective rankings of risk is therefore a requirement for biodiversity conservation, as invertebrates represent the vast majority of described species (approximately 80\%).

Critical to conserving biodiversity is understanding the status of and trends in the distribution and abundance of species (Gaston, 1994, 2003; Baillie et al., 2008). However, monitoring populations of rare species is a challenging process (Stork et al., 1996). The IUCN Red List is arguably the most useful worldwide list of species at risk of extinction (Lamoreux et al., 2003). Its usefulness is based on its reliance on a number of objective criteria, which are relatively easy to apply when adequate information is available (IUCN, 2001; Table 1). The Red List has been used to raise awareness about threatened species, guide conservation efforts and funding, set priorities for protection, measure site irreplaceability and vulnerability, influence environmental policies and legislation and evaluate and monitor the state of biodiversity (Gärdenfors et al., 2001; Rodrigues et al., 2006; Baillie et al., 2008; Mace et al., 2008; Martín-López et al., 2011). The IUCN classifies species into different 
Table 1

Overview of the IUCN Red List criteria (AOO - Area of Occupancy; EOO - Extent of Occurrence; $n$ - mature individuals).

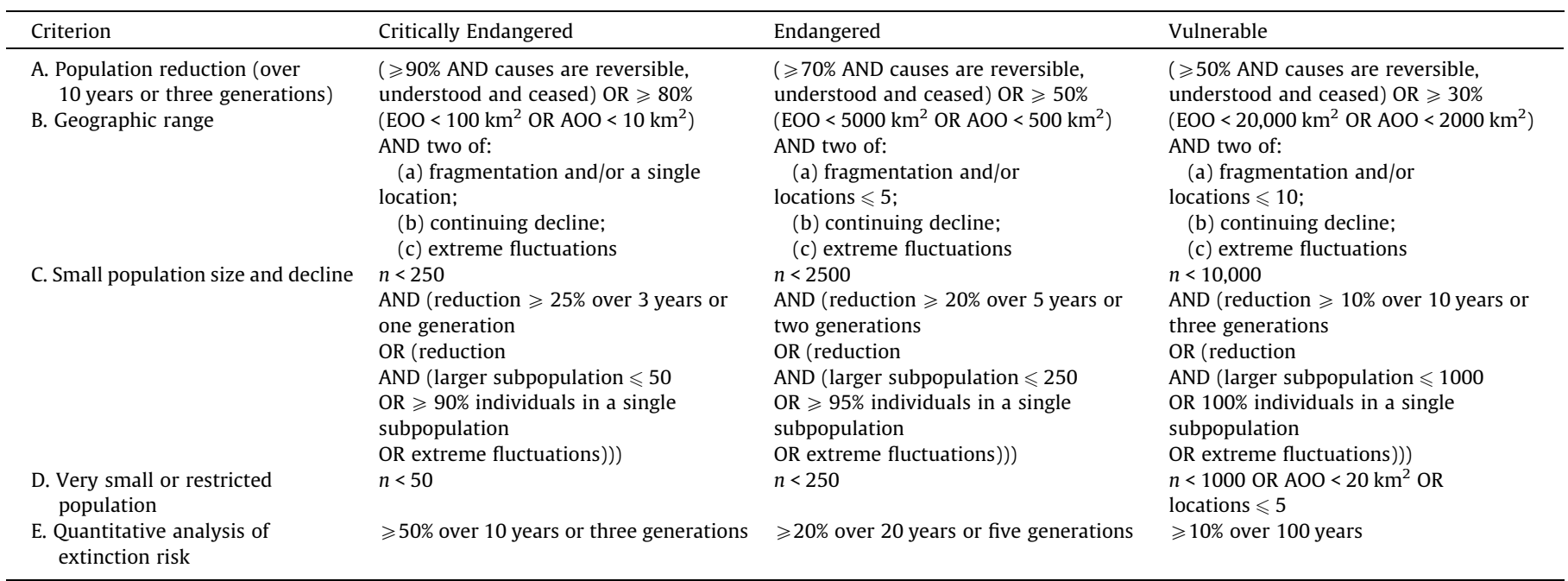

risk categories with evocative titles, namely Critically Endangered (CR), Endangered (EN) and Vulnerable (VU). However, these classifications are more relative than absolute in the sense that a classification of CR does not imply that the species is almost extinct but only that it is in greater danger of becoming extinct, even if by socalled stochastic effects, compared to a species that is classified in any other category. Within such a framework, it is important that the different criteria and thresholds have discriminative powers that allow the ranking of species according to their level of extinction risk. Of the many uses of the Red List, such ranking of species is paramount when establishing priorities for protection and for justifying funding for conservation (Rodrigues et al., 2006; Baillie et al., 2008; Mace et al., 2008).

Although the criteria were meant to be applicable to the majority of described species, the taxonomic bias is striking (Lozano et al., 2007). While almost all of the mammalian, avian and amphibian species have been evaluated, only $0.5 \%$ of the described arthropod species and $4 \%$ of all described molluscs worldwide have been evaluated (IUCN, 2010), most of which are butterflies (Lewis and Senior, 2011), dragonflies (Clausnitzer et al., 2009) and freshwater crabs (Cumberlidge et al., 2009). This reveals a bias towards large species with wide distribution ranges and high dispersal abilities, i.e., those that are easily sampled. Thus, the current Red List omits small species with narrow distribution ranges and low dispersal abilities, which constitute the vast majority of the planet's biota, particularly local endemics. Consequently, the most threatened invertebrate species are likely excluded. To avoid this bias, species evaluations often do not justify the numerical values used as recommended by IUCN (see the minimum requirements in Annex III of IUCN, 2001), and are instead based solely on expert opinions about changes in the species' abundance and distribution, which reduces the objectivity of the assigned risk category (Verdú and Galante, 2006).

In addition to invertebrates, other taxa face similar difficulties. For example, small herbaceous species (Lozano et al., 2007), bryophytes (Hallingbäck et al., 1998; Hallingbäck, 2007), fungi and lichens are also often neglected. This taxonomic bias is also pervasive in species inventories (Gaston and Rodrigues, 2003; Pressey, 2004), species reintroduction projects (Seddon et al., 2005), invasive species studies (Pysek et al., 2008), legally protected species lists and consequently, funding for species conservation (Clark and May, 2002; Martín-López et al., 2009, 2011).

Two reasons justify the current taxonomic bias of the IUCN lists. First, the current criteria are difficult to apply using the information that can be reasonably gathered for most invertebrate species (New and Sands, 2003; Kozlowski, 2008) because of four main shortfalls (see Cardoso et al., in press): (1) most species are undescribed (the Linnean shortfall); (2) the distributions of described species are largely unknown (the Wallacean shortfall); (3) species' abundances and their changes in space and time are unknown (the Prestonian shortfall); and (4) species' ecology and sensitivity to habitat changes are largely unknown (the Hutchinsonian shortfall). These four shortfalls stem from the fact that basic research on invertebrates, especially concerning their taxonomy and natural history, is scarce and underfunded (the scientific dilemma, see Cardoso et al., in press). This poor knowledge makes it difficult to gather enough information to classify most species into any risk category. The criteria should be adapted in some way to increase the feasibility of the classifications. Second, a critical look at the Red List's thresholds suggests that they were defined based on the requirements of large vertebrate species. Even if enough information could be gathered, the current criteria may not be appropriate for most invertebrates. Thus, the criteria should be modified to increase the adequacy of the classifications. When both feasibility and adequacy are achieved, invertebrates will represent a significant proportion of the priority species lists and taxonomic balance can be realized (e.g., Martín et al., 2010).

By evaluating each IUCN criterion separately, we intend to accomplish the following tasks:

(1) identify the shortcomings of the application of the current criteria to invertebrate species, particularly to the hyperdiverse arthropods;

(2) explain how the risk categories may be erroneously applied due to biologically unrealistic and/or misleading thresholds (causing extinction risks to be under- or over-estimated);

(3) suggest alternative approaches of applying the existing criteria in a more realistic way considering the biological, ecological and biogeographic attributes of invertebrates;

(4) suggest the incorporation of new criteria to allow a more comprehensive and effective assessment of invertebrates.

Our intention is to initiate a discussion about the need to revise the existing IUCN criteria and thresholds and to introduce new criteria that will complement the existing ones for a more realistic evaluation of the vast majority of the planet's species, i.e., invertebrates. We do not intend to propose a change to the current IUCN 
framework, which has been applied widely, even at the global scale for vertebrates. Such a dramatic change could have undesirable consequences on the Red List's long-term benefits (Mace et al., 2008).

\section{Shortcomings and possible alternatives to the current criteria}

\subsection{Population reduction - Criterion A}

This criterion is based on the reduction of the number of individuals of a given species (Table 1 ). However, obtaining abundance data is particularly difficult for invertebrates, and it is usually impossible to estimate the absolute abundance of a species. Because of this, it is also very difficult to assess changes in their abundance through time. Monitoring population changes requires a very thorough sampling program replicated at least twice, 10 years apart to meet the IUCN criteria, but further sampling efforts would be required to distinguish between natural fluctuations and a real decline (Fox et al., in press). This kind of long-term ecological monitoring is very rare for invertebrates. Such monitoring has been restricted mainly to butterflies (van Swaay et al., 2008; Lewis and Senior, 2011), allowing the publication of red lists (van Swaay et al., 2010, 2011; Fox et al., in press) and the selection of priority areas for conservation (van Swaay and Warren, 2006).

Abundance is usually correlated with the range of a species (the intraspecific range-abundance correlation; Gaston, 1994). Therefore, one alternative is to use estimates of the reduction in the Area of Occupancy (AOO) as a surrogate for suspected reductions in population abundance. Nevertheless, the relationship between range size and abundance, although generally true, is not inevitable, and it must be justified in IUCN evaluations (Akçakaya et al., 2006). In fact, if it is generally true that no restricted species is locally abundant, some species can occupy many sites but have only small population sizes in most of them (the triangular intraspecific rangeabundance relationship; Gaston, 1994). An additional problem is that any decline in AOO is usually inferred from a decline in habitat extent and/or quality. This makes most inferences about abundance declines in populations indirect deductions. Such inferences assume first, that point abundance is the same everywhere inside the $\mathrm{AOO}$ and second, that $\mathrm{AOO}$ follows the same decline as habitat.

Instead of relying on overwhelmingly difficult to obtain (abundance) or indirect (distribution) data, we suggest the modification of this criterion to incorporate declining range size. This could be based on declining AOO using the same thresholds as population reduction. This would better reflect the type of data that is possible to obtain for invertebrates and increase the feasibility of evaluations, leading to a decrease in the number of species classified as Data Deficient (DD). This process has been successfully tested in the evaluation of the conservation status of threatened species in the Canary Islands, which included different species of arthropods (Martín et al., 2005). The Canary Islands Government has incorporated the list in its regional legislation.

\subsection{Geographic range - Criterion B}

This criterion is based on the range size of a species (AOO or Extent of Occurrence, EOO) and possible fragmentation, decline or extreme fluctuations (Table 1). The EOO is defined by the IUCN as, the area contained within the shortest continuous imaginary boundary that can be drawn to encompass all sites of present occurrence of a taxon'. The AOO represents the area currently occupied and is a function of the scale (e.g., spatial resolution) at which it is measured (see Gaston, 2003). It is the only existing criterion that can be properly applied to most species (Lewis and Senior, 2011). However, the threshold values do not seem appropriate for many taxa. Organisms with small body sizes usually require much smaller areas than organisms with larger body sizes, and invertebrates typically have smaller ranges than vertebrates, with plants presenting intermediate values (Gaston, 2003; Martín, 2009). Especially among island endemics (Martín, 2009) and troglobionts, many species meet some threshold of criterion B, including many vertebrates, even if they are naturally rare and not, therefore, necessarily endangered. This may lead to an overestimation of extinction risk.

The IUCN recognizes that this criterion is especially difficult to meet because the use of AOO or EOO is not as robust as using the number of individuals. Therefore, three conditions have to be met for each species considered: small range, habitat fragmentation and range decline (Table 1). Extreme fluctuations are usually difficult to assess. This means that non-insular and non-troglobiont species may not meet the requirements of Criterion B even if they are endangered. Therefore, classifications may also underestimate the real risk of extinction.

Finally, incomplete sampling is the rule rather than the exception with invertebrates. The fact that a species is not known from a given region does not mean it is not present; often simply no one has searched for it. This causes the EOO and AOO of many species to be underestimated unless corrections are made. Such corrections are essential for many species described from a restricted number of individuals found in a single or few locations, which have not been further studied after their original description. Classifications based on incomplete sampling may overestimate the real risk of extinction.

As an alternative to the current criteria, we suggest that two different approaches could be used to classify a species into a risk category. Either a large EOO or AOO along with two extra criteria or a small AOO or EOO and a single extra criterion could be used for classification. This would increase both the feasibility, by requiring less data in many situations, and adequacy, by reducing the threshold distribution ranges for classification.

We also propose two alternatives to solve the problem of incomplete sampling. First, for habitat specialist species with restricted distributions, the area of its habitat in a region could be a good surrogate for the total area occupied by that species.

Second, for all other species, ecological modelling of species distributions may be a good option for reducing bias. Many different techniques for modelling species distributions exist (e.g., Elith et al., 2006) and their output is often divergent. Maximum entropy (Phillips et al., 2006) is often considered one of the most accurate (Elith et al., 2006), but ensemble forecasting, a technique that combines a variable number of modelling techniques and reaches a consensus distribution of species, may in many cases be more accurate (Araújo et al., 2005; Thuiller et al., 2009). In order to reduce these models' errors, in addition to climatic variables, variables directly related to habitat suitability, such as land cover and human population density, should be used. All of these techniques produce a map of potential distribution probabilities or habitat suitability as the output. Such a map should be converted to a binary presence/absence map to calculate AOO and EOO. The threshold above which a species should be considered as present is variable, but a few rules have been found to perform well (Liu et al., 2005). After conversion, the EOO can be calculated as the area of the convex-hull polygon encompassing all the sites predicted as suitable for a species. The area occupied by such sites is the AOO and is nearly always smaller than the EOO.

It should be noted that the output of ecological models are maps of potential distributions, not realised distributions, which can be different due to historical (e.g., geographical barriers, local extinctions caused by habitat destruction) or biological (e.g., competition, dispersal capacity) reasons. In addition, using such techniques makes it virtually impossible to calculate the number of 
locations as defined by the IUCN. These kinds of techniques are only now beginning to be widely used for conservation purposes, with only a few cases pre-dating the current IUCN criteria. The application of ecological modelling should be considered in the future, particularly for invertebrate species or other taxa for which information will probably never be complete. The best way to use distribution modelling to conduct Red List classifications is an area that deserves further study.

\subsection{Small population size and decline - Criterion $C$}

This criterion is based on the number of individuals in a species and the possibility of their decline or extreme population fluctuations (Table 1). Even when it is possible to estimate the number of individuals by exhaustively conducting standardized sampling in a limited set of small areas and extrapolating (see Stroot and Depiereux, 1989), the current threshold values are inadequate. Mace et al. (2008) justify the use of the current population size thresholds because "demographic stochasticity is unlikely to be important for any population that has more than about 100 individuals". However, most invertebrate species would probably be condemned to extinction by demographic stochasticity if only 100 individuals were living, given the relatively low probability that each individual finds a partner, mates, lays eggs and, in many cases, raises the juveniles until they are independent, therefore ensuring the survival of the next generation. The current IUCN population thresholds simply have no reasonable application for most invertebrate species and therefore most extant global species richness. This may lead to an underestimation of extinction risk.

The thresholds of abundance should increase to numbers that reflect realistic values for invertebrates, possibly a few orders of magnitude higher than the current ones, thereby increasing their adequacy. Given the large variability in body size of invertebrates, from dozens of microns (Cycliophorans) to more than a dozen metres (squid), the thresholds in abundance could be variable and likely even inversely correlated with body size.

\subsection{Very small or restricted population - Criterion D}

This criterion is based on the number of individuals of a species or a species found in a restricted range or number of locations (Table 1 ). As with the previous criterion, even when it is possible to estimate the number of individuals of a species, the current threshold values are clearly inadequate. Likewise, therefore, this criterion can lead to an underestimation of extinction risk for invertebrates.

As in the previous criterion, the thresholds of abundance should be increased to adequate numbers. Additionally, given that estimating absolute abundance data is very difficult, we suggest that the AOO could be used as a sufficient criterion for more categories than Vulnerable (Table 1). Many invertebrate species are confined to extremely small areas (even less than 1 ha), and a single event could drive them to extinction even if they are not currently in decline. Such events, if considered as plausible near-future threats (e.g., pollution spills, nearby active volcanoes) could be used to justify listing an extremely restricted species as CR or EN. In this way, the applicability of this criterion would increase by allowing the use of AOO to classify a species into any category.

\subsection{Quantitative analysis of extinction risk - Criterion $E$}

This criterion is based on a quantitative analysis of extinction risk (Table 1), usually population viability analysis (PVA). This technique has seldom been applied to invertebrates or other small-bodied organisms (Schultz and Hammond, 2003; Bergman and Kindvall, 2004). In fact, as recognized by the IUCN, this crite- rion requires the most exhaustive data and is difficult to apply even for many vertebrate taxa.

However, PVA is not the only method for the quantitative analysis of extinction risk, and it should be possible to analyse extinction risk in situations of restricted habitat and predictable habitat disappearance (including co-extinction, see below). Moreover, decreases in habitat quality can also have major impacts on population persistence (Schultz and Hammond, 2003). Because there is an extinction debt between the time of habitat disappearance and species extinction (Tilman et al., 1994; Triantis et al., 2010) their correlation is not straightforward. This criterion should therefore explicitly incorporate the probability of habitat disappearance for species with restricted habitat types. In this way, the applicability of this criterion for invertebrate species would increase.

Projections of global warming and its consequences on species usually consider 50-100 years into the future. Given the oftenshort generation time of invertebrates, using such projections may prove especially useful for classifying species into the Vulnerable category (Table 1 ). It is, however, extremely difficult to provide exact probabilities of extinction in a given time frame as required by the current criterion (Akçakaya et al., 2006). The quality of data is especially critical for projections using the many different long-term climate change scenarios that are available, and extinction debt must also be taken into account. Determining the most appropriate way to incorporate future projections of AOO and the respective change from the present AOO, perhaps by using ecological modelling (e.g., Araújo et al., 2005), is an additional area that should be considered for future studies.

\subsection{Co-extinction}

Invertebrates are prone to extinction factors that rarely affect vertebrates (Dunn, 2005). Many species are dependent on a single host, prey or other species that are, for various reasons, essential to their survival. This includes monophagous predators and herbivores and single-species parasites or parasitoids. In fact, it has already been suggested that co-extinction may be the most common form of extinction (Koh et al., 2004; Dunn et al., 2009). Such dependency may occur at any life stage (eggs, larvae, juveniles or adults) or sex (often males and females do not overlap in their use of resources).

If a host or prey species is listed in any category, the dependent species should be immediately considered in same category without further justification. Although this can be justified with the current criteria, it is usually only through indirect evidence of the inferred decline of the population.

\section{Case studies}

\subsection{Datasets}

To test the application of the criteria to various invertebrate taxa in different regions, we have compiled information for two comprehensive datasets, each with 24 species, for a total of 48 species evaluated (Appendix 1). We restricted our analyses to species endemic to each region to perform global evaluations. The given datasets were chosen because data were relatively comprehensive, publicly available and familiar to the authors.

The first dataset was composed of arthropod species endemic to the Azores archipelago. The arthropod fauna of the Azores is particularly well known because standardized sampling has been performed over the last 10 years in all of the remaining natural forests on the islands (Borges et al., 2005; Gaspar et al., 2008, in press). In addition, work has recently been performed using the same sampling protocol in other types of habitats, including heav- 
ily impacted ones (Cardoso et al., 2009; Meijer et al., 2011). A thorough sampling of caves in the archipelago has also provided much of the data (Amorim, 2005; Borges et al., 2007). In addition to these data, comprehensive distribution data were available and have been compiled into a recent catalogue and public database (Borges et al., 2010). The 24 species were equally divided into natural forest specialists (eight species; see definition in Triantis et al., 2010), underground cave-dwelling animals (eight species) and species from other habitat types (eight species) because we believed that this a priori division could balance the inclusion of endangered and common species.

The second dataset was composed of spider species endemic to the Iberian Peninsula. Some spider families in Portugal and Spain are relatively well known, with standardized sampling performed over the last 10 years in different habitat types in Portugal (Cardoso, 2009). Caves were also sampled in many of the karstic areas of the region, providing much of the data. In addition to these data, distribution data were available and have been compiled into a recent catalogue (Cardoso and Morano, 2010). The 24 species were divided into troglobionts (eight species), Dysderidae (eight species) and Zodariidae (eight species) because these are the best known groups among the most speciose taxa.

Each of the six groups of eight species was divided into three sub-groups. Two species were chosen ad hoc from those considered by the authors to be rare and in need of protection. Two were also chosen ad hoc from those considered by the authors to be common and in no need of protection. The remaining four species per group were chosen randomly from all endemic species described in order to provide an estimate of the general patterns that would emerge if all species were evaluated in a way similar to the Sampled Red List Index approach (Clausnitzer et al., 2009; Cumberlidge et al., 2009; Lewis and Senior, 2011).

\subsection{Evaluation of criteria}

The AOO was defined differently according to the taxa. For the Azorean forest species, the AOO was calculated as the sum of the area of the forest patches where each species was known to reside. Because all forest patches were thoroughly sampled, this measure should be considered as precise, although overestimated in a few cases where the species does not occupy the entire forest area, e.g., at the disturbed borders (Borges et al., 2006; Cardoso et al., 2007, 2009). For Azorean species occupying other habitat types, the AOO was calculated in the same way. However, for species found in large numbers in disturbed habitats, the entire area of that habitat type on the islands where the species occurred was used instead of only the patches known to be occupied. This was based on the assumption that species able to occupy disturbed habitat types could easily be present in similar, unsampled patches of habitat. For troglobiont species, in either the Azores or the Iberian Peninsula, the approximate area of the cave systems occupied by the species was used. Because caves belonging to the same system are usually connected, we assumed that the entire area could be part of the AOO even if the species may not have occupied the entire system.

For epigean species on the Iberian Peninsula (Dysderidae and Zodariidae), we calculated the potential distribution using the maximum entropy method with Maxent software (Phillips et al., 2006). Eleven spatial variables were used for this modelling, all with a resolution of one square kilometre: (1) annual mean temperature; (2) temperature seasonality; (3) annual precipitation; (4) precipitation seasonality; (5) potential evapotranspiration; (6) NDVI; (7) land cover; (8) human population density; (9) altitude; (10) latitude; and (11) longitude. The continuous probability maps generated by this method were then converted to presence-absence maps using an option that equalized sensitivity and specific- ity as the threshold (Liu et al., 2005). Each site evaluated as suitable for the species was considered part of the AOO.

In the current study, EOO was defined by the minimum convex polygon joining all the occurrences of a species, as suggested by the IUCN guidelines. The exception, following the IUCN recommendations, was with species in the Azores that live on different islands. In such cases, the total EOO was calculated as the sum of the polygons on each island because including the sea between the islands would artificially increase the EOO by several orders of magnitude. For the species whose AOO was calculated based on distribution modelling, the EOO was the area of the polygon encompassing the entire potential AOO.

The number of locations was calculated per the IUCN guidelines as "a geographically or ecologically distinct area in which a single threatening event can rapidly affect all individuals of the taxon present". In some cases, this was a subjective decision because the extent of future threatening events was difficult to quantify. The number of locations of the species modelled using Maxent was impossible to determine.

The possible decline and the causes for decline or extreme fluctuations in the EOO, AOO or number of locations were evaluated according to the known history of the habitat (e.g., loss, fragmentation, invasion by exotic species). The percentage of decline was impossible to calculate for all cases except for Anapistula ataecina, whose habitat is being eliminated by stone quarries (Cardoso and Scharff, 2009). We were able to infer declines in habitat quality for most species inhabiting one or a few habitats. Fragmentation of subpopulations was assumed if the habitat was fragmented without adequate corridors between the patches; this was usually the case for Azorean forest specialists and for all troglobionts.

We had no abundance data or even rough estimates of abundance for any of the species. Instead of considering this value as unknown, we used the arbitrary abundance of $1,000,000$ for all species. Using this value allowed us to obtain classifications for many species that would be evaluated as DD if "Unknown" were used. Because we used a conservative value that was far above the abundance thresholds defined by any of the criteria, we could avoid the classification of any species as at risk based in any way on abundance values.

Given the uncertainty that inevitably arises when many of the parameters are unknown, we used the RAMAS software package (Akçakaya and Ferson, 2001) to build a file for each species and reach a single classification (all files are available from the first author by request). In cases of uncertainty, we used the most plausible classification given by the software, as suggested by Colyvan et al. (1999).

\subsection{Results}

The EOO and AOO for most species were below the thresholds needed to classify any species as at risk, even for some common species (Fig. 1; Appendices 1 and 2). For the Azores dataset in particular, all species necessarily had an EOO and AOO smaller than the area of the archipelago $\left(2346 \mathrm{~km}^{2}\right.$; Fig. 1). Moreover, being an archipelago with large distances between islands, many species that live on more than one island fulfilled the fragmentation subcriterion (B1a), and most single-island endemics fulfilled the number of locations sub-criterion (B1a). This implied that most endemic species with any kind of decline were immediately classified at least as EN (Appendix 1). This criterion was also met by the cave-dwelling species we assessed, with all troglobionts classified as either CR or EN, unless the information available was scarce and an assessment of DD was reached (Appendix 1). In fact, one-third of the 48 species had an EOO below the threshold for a classification of CR $\left(100 \mathrm{~km}^{2}\right)$ and one-quarter presented an AOO below the threshold for the same classification $\left(10 \mathrm{~km}^{2}\right)$. 


\section{Extent of occurrence}
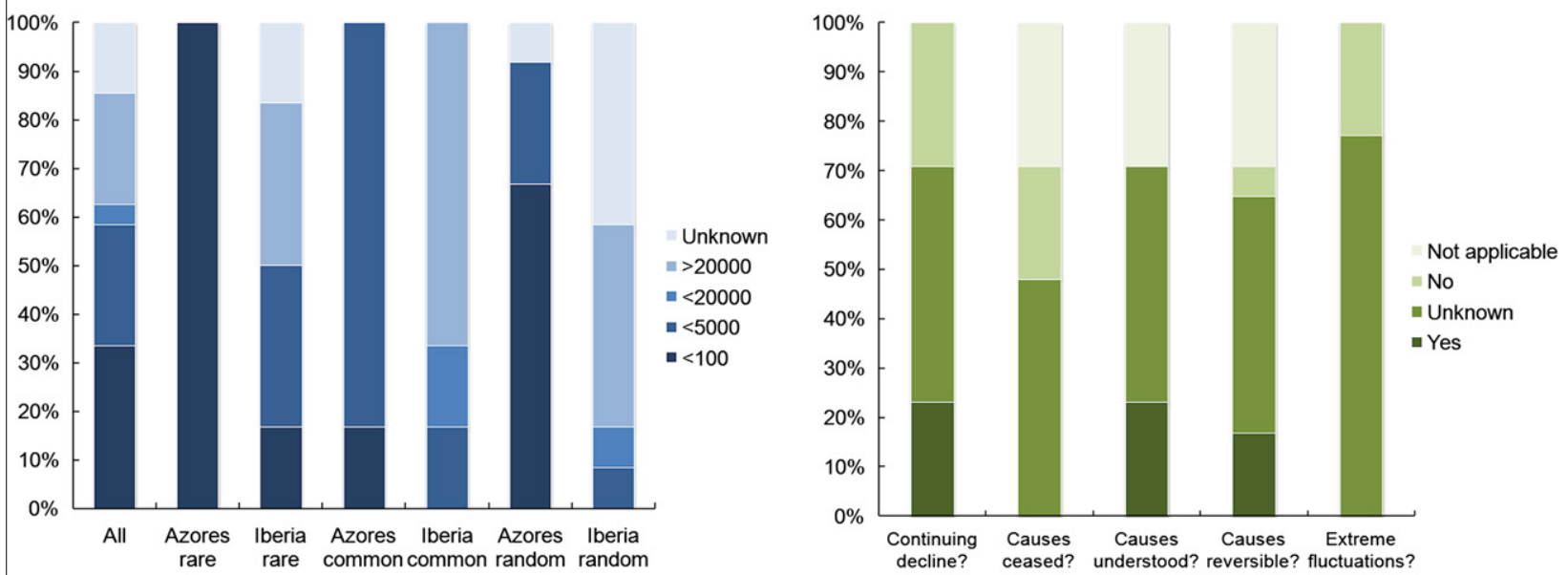

\section{Area of occupancy}
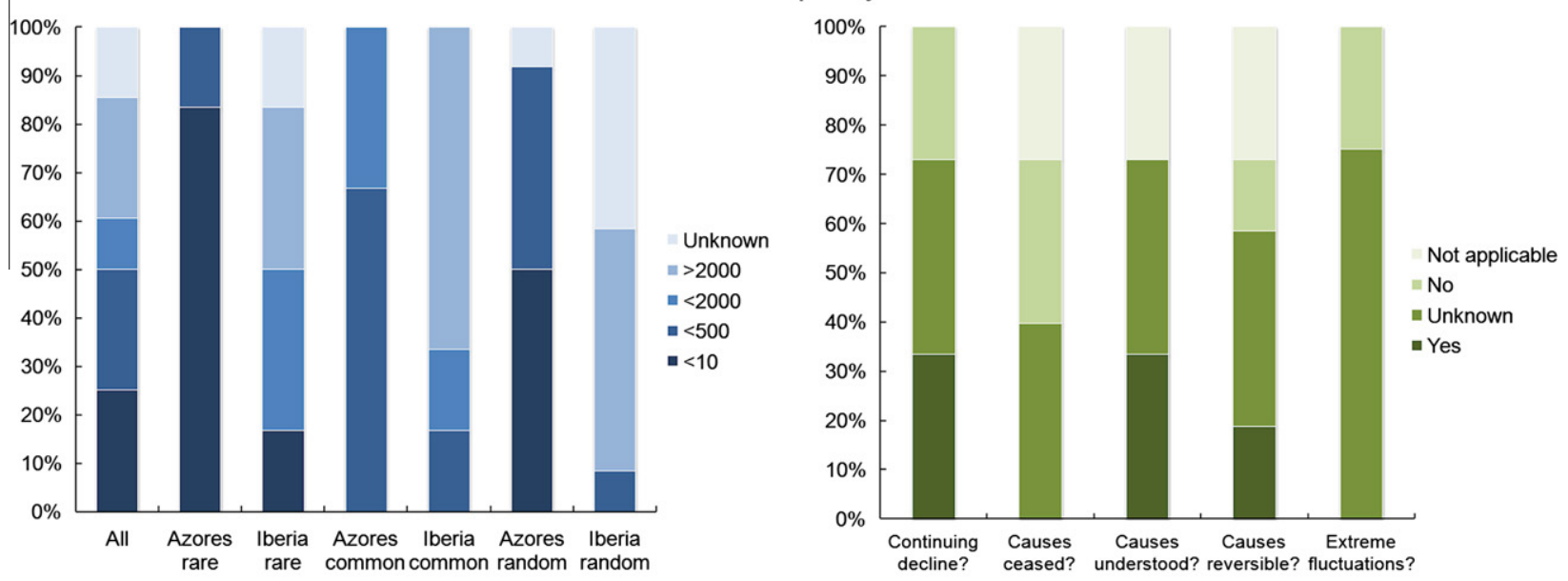

\section{Locations}
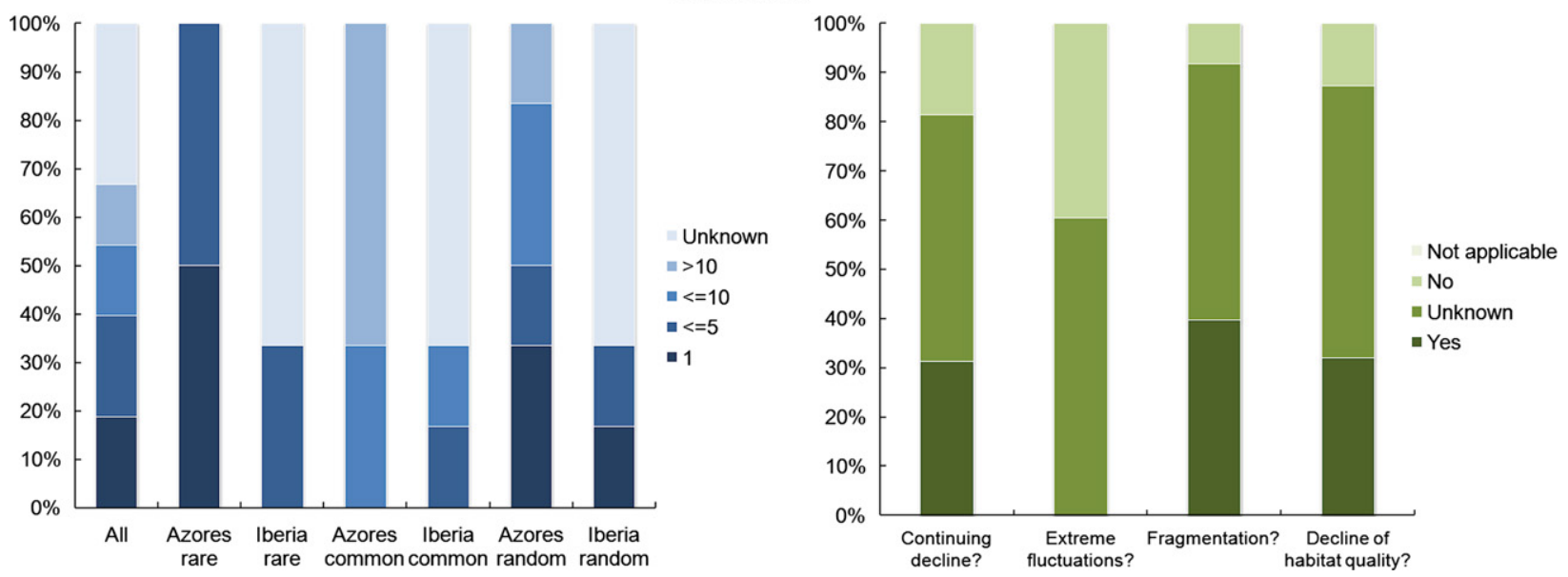

Fig. 1. Data of extent of occurrence, Area of Occupancy and number of locations for the 48 species evaluated in this study.

In many cases, it was impossible to assess whether there was a continuing decline in EOO or AOO and, if so, the causes (Fig. 1; Appendix 1). Such assessment was only possible for species with restricted habitat preferences where the decline was inferred from a decline in habitat area and/or quality. Extreme fluctuations were impossible to assess in all but a few species that were very common and therefore did not present such fluctuations.
The number of known locations was low in most cases except for species classified a priori as common (Fig. 1). A continuous decline in the number of locations was impossible to assess in half the cases. When it was possible to reach some conclusion, it was necessary to infer a decline in the number of locations from a decline in AOO, which, as described above, was inferred from a decline in habitat area and/or quality. 
Fragmentation was a common situation, given the number of insular, habitat specialist and troglobiont species in our datasets. For habitat generalists, fragmentation was usually classified as unknown. Determining declines in habitat quality followed the same trend as fragmentation, as the two concepts are necessarily interconnected.

As mentioned above, absolute abundances, even if roughly estimated, were impossible to obtain for any species (Appendix 1). Long-term population monitoring of only one species, Trechus terceiranus, has been performed. However, even after years of study, only the tendencies (decreasing) and not the absolute numbers are known (Borges et al., 2007; Borges and Pereira, unpublished data). Even for this well-studied species, it was impossible to determine the percentage decline in the number of individuals over the years. Therefore, these values all had to be inferred from perceived declines in the AOO, which were themselves inferred from declines in habitat area and/or quality, as described above. In all cases, it was not possible to determine the proportion of individuals in the largest subpopulation or whether there were extreme fluctuations in abundance.

It was impossible to obtain the probability of extinction within a given time frame due to the requirement for unavailable data (Appendix 1). At a minimum, it would be necessary to know the rate of future disappearance of adequate habitat. However, these data were not available at the time of writing.

More than one-quarter (27\%) of the 48 evaluated species were classified as Critically Endangered, 19\% as Endangered, 6\% as Vulnerable and $8 \%$ as Least Concern. The remaining $40 \%$ did not have enough data to reach a classification (Fig. 2).

If we only took into account the 24 randomly chosen species, the numbers changed but the trends were similar (Fig. 2). Remarkably, not a single species chosen randomly could be considered as Least Concern (LC), and more than half the species, mostly Iberian spiders, had to be classified as DD due to the lack of appropriate data. This meant that all species were classified as in risk of extinction to some degree.

\subsection{Feasibility and adequacy of species evaluations}

In many cases, all the information available about each of the species evaluated was insufficient to reach an assessment. Assessments were possible only for those species with relatively wellknown distribution (allowing the estimation of EOO and AOO) and restricted habitats (allowing the evaluation of fragmentation and habitat quality) that had been studied with quantitative methods (allowing the evaluation of possible declines). When these three requirements were fulfilled, the Wallacean, Prestonian and

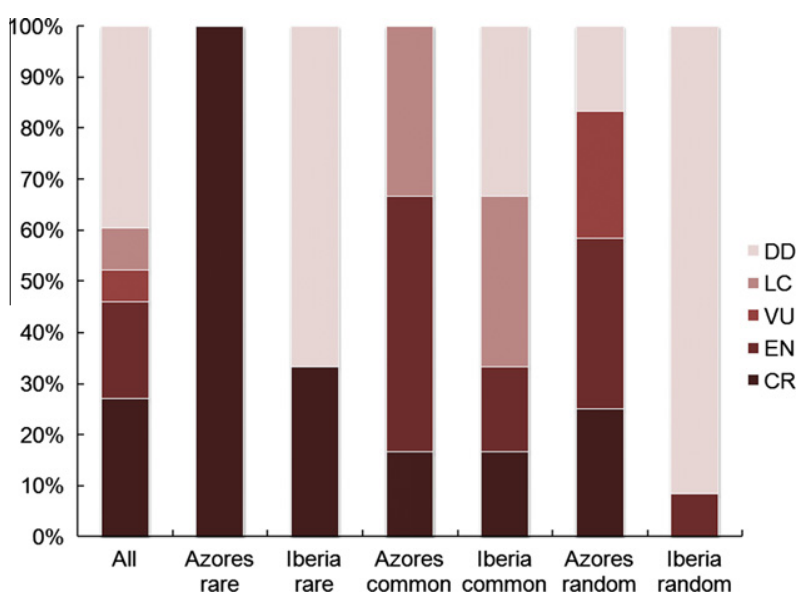

Fig. 2. Classifications reached for the 48 species evaluated in this study.
Table 2

Overview of shortcomings of the current criteria and possible alternatives for invertebrates (AOO - Area of Occupancy; EOO - Extent of Occurrence).

\begin{tabular}{|c|c|c|}
\hline Criterion & Shortcomings & Alternatives \\
\hline $\begin{array}{l}\text { A. Population } \\
\text { reduction }\end{array}$ & $\begin{array}{l}\text { Abundance decline difficult to } \\
\text { measure }\end{array}$ & $\begin{array}{l}\text { Use declining } \mathrm{AOO} \text { as } \\
\text { alternative to } \\
\text { abundance }\end{array}$ \\
\hline \multirow[t]{3}{*}{$\begin{array}{l}\text { B. Geographic } \\
\text { range }\end{array}$} & $\begin{array}{l}\text { EOO and AOO very large for } \\
\text { invertebrates }\end{array}$ & $\begin{array}{l}\text { Reduce EOO and AOO } \\
\text { thresholds }\end{array}$ \\
\hline & $\begin{array}{l}\text { Hard to meet all } \\
\text { requirements (small range, } \\
\text { fragmentation, decline) }\end{array}$ & $\begin{array}{l}\text { Stipulate less } \\
\text { requirements }\end{array}$ \\
\hline & Incomplete sampling & $\begin{array}{l}\text { Habitat area for habitat } \\
\text { specialist species } \\
\text { Ecological modelling }\end{array}$ \\
\hline $\begin{array}{l}\text { C. Small } \\
\text { population } \\
\text { size and } \\
\text { decline }\end{array}$ & $\begin{array}{l}\text { Inadequate threshold values } \\
\text { for abundance }\end{array}$ & $\begin{array}{l}\text { Increase abundance } \\
\text { thresholds }\end{array}$ \\
\hline \multirow{2}{*}{$\begin{array}{l}\text { D. Very small or } \\
\text { restricted } \\
\text { population }\end{array}$} & $\begin{array}{l}\text { Inadequate threshold values } \\
\text { for abundance }\end{array}$ & $\begin{array}{l}\text { Increase abundance } \\
\text { thresholds }\end{array}$ \\
\hline & $\begin{array}{l}\text { Abundance data hard to } \\
\text { obtain }\end{array}$ & $\begin{array}{l}\text { Use } A O O \text { as alternative } \\
\text { to abundance }\end{array}$ \\
\hline $\begin{array}{l}\text { E. Quantitative } \\
\text { analysis of } \\
\text { extinction risk }\end{array}$ & $\begin{array}{l}\text { Very difficult to apply } \\
\text { without a large amount of } \\
\text { data }\end{array}$ & $\begin{array}{l}\text { Use habitat } \\
\text { disappearance for } \\
\text { habitat specialist } \\
\text { species } \\
\text { Use future projections } \\
\text { of EOO and AOO }\end{array}$ \\
\hline F. Co-extinction & Not considered & $\begin{array}{l}\text { Dependent species with } \\
\text { same category as host/ } \\
\text { prey }\end{array}$ \\
\hline
\end{tabular}

Hutchinsonian shortfalls (see Cardoso et al., in press) could be overcome and a classification reached.

Paradoxically, it seems to be harder to obtain reliable information for common species. If a species is restricted in area and habitat type, it is relatively easy to relate habitat loss with loss of EOO or AOO. If a species is not restricted to a small area or a unique habitat, it becomes a daunting task to determine its current trends. However, common species could also have a declining trend in both abundance and distribution (Gaston, 2010). Thus, the feasibility of the current criteria is compromised. A further consequence of this paradox is that almost all species that were possible to be evaluated, even species considered $a$ priori as common and non-endangered, were classified as at risk, most commonly as Critically Endangered. This is more evident for the island species, which could create the "island artefact" (overestimation of risk) because the small size of islands manifests in most single-island endemic species being easily classified into one of the IUCN categories (Martín, 2009). The adequacy of the current criteria is therefore also compromised. If both feasibility and adequacy seem to be far from ideal, the discussion of a number of improvements to the current criteria seems to be necessary (Table 2).

\section{Conclusions}

The evaluation of risk and the ranking of species based on extinction risk is the objective of the IUCN Red List criteria. However, we argue that the current criteria may present serious shortcomings when applied to the majority of invertebrate groups (Table 2), and thus to the majority of known species. The criteria should be both feasible, in the sense that the information required should be obtainable without an unreasonable effort, and adequate, in the sense that the criteria should allow realistic ranking of species according to their extinction risk.

A prevailing issue in the classification of invertebrate species (and probably many plant and fungi taxa) according to the current 
criteria is subjectivity (Lewis and Senior, 2011). As mentioned above, many trends are inferred from indirect evidence and the methods for determining them largely depend on the perception of each evaluator at each moment (Verdú and Galante, 2006). This means that the seemingly objective criteria often are subjectively applied. Subjectivity is even more influential if many taxa are being evaluated simultaneously and the evaluators avoid assigning species to the DD status.

The application of the current criteria to invertebrates is mostly limited to criterion B (e.g., Lewis and Senior, 2011) and in some cases A or D (van Swaay et al., 2010; Fox et al., in press; Lewis and Senior, 2011). Therefore, adapting the criteria to explicitly incorporate measures of $\mathrm{AOO}$ and $\mathrm{EOO}$ in addition to population size is critically important to overcome the feasibility problems and allow the proper application of criteria A, C (in some cases) and $D$. Criterion E could also be modified to ensure easy implementation for habitat-restricted species or those that are predicted to be most affected by climate change. Additionally, co-extinction could be included as part of the process (Table 2). As the criteria are currently defined, they seem targeted toward the exceptions in data availability rather than the rule.

Adequacy problems are probably more difficult to overcome. This implies either that changes should be made to the current threshold values for invertebrates or that sub-categories should be created to guarantee comparability with other taxa. Dividing each extinction risk category into sub-categories would allow better discrimination between rare and relatively common species that are currently listed in the same category. This discrimination would increase the adequacy of the current criteria.

Given reasonable information and adequate criteria, it is possible to evaluate all taxa in an unbiased and objective manner, from the smallest insect to the largest mammal (Martín et al., 2010). Our proposal is intended to promote debate among experts. Having a parallel set of criteria for invertebrates, and eventually for other little-known taxa, would allow experts to fill in the gap that currently exists between the number of assessed species and the number of described species. With the current rate of species description (15,000 invertebrate species per year, see: http://www.organismnames.com), this gap is, in fact, increasing every day.

Finally, we emphasize that red lists are not usually equivalent to legally protected species lists (Martín et al., 2010). Translating a list of endangered species to binding law is a final, essential, step in the adequate protection of our biodiversity. Using a set of objective criteria to create red lists and, in later stages, protected species lists, would allow prioritizing species protection in a rigorous, efficient way.

\section{Acknowledgements}

PC is supported by the Portuguese Foundation for Science and Technology (SFRH/BPD/40688/2007). The data obtained in the Azores was possible due to the accumulated effort of many colleagues during BALA Project (funded by the Direcção Regional dos Recursos Florestais - Proj. 17.01-080203) and more recently the projects "Consequences of land-use change on Azorean fauna and flora - the 2010 Target" (Ref: Direcção Regional da Ciência e Tecnologia M.2.1.2/I/003/2008) and FCT-PTDC/BIA-BEC/100182/ 2008 - "Predicting extinctions on islands: a multi-scale assessment".

\section{Appendix A. Supplementary material}

Supplementary data associated with this article can be found, in the online version, at doi:10.1016/j.biocon.2011.06.020.

\section{References}

Akçakaya, H.R., Ferson, S., 2001. RAMAS ${ }^{\circledR}$ Red List: Threatened Species Classifications under Uncertainty. Version 2.0. Applied Biomathematics, New York.

Akçakaya, H.R., Butchart, S.H.M., Mace, G.M., Stuart, S.N., Hilton-Taylor, C., 2006. Use and misuse of the IUCN Red List criteria in projecting climate change impacts on biodiversity. Glob. Change Biol. 12, 2037-2043.

Amorim, I.R., 2005. Colonization and diversification on oceanic islands: forest Tarphius and cave-dwelling Trechus beetles of the Azores. Ph.D. dissertation, Department of Ecology and Evolutionary Biology, University of California, Los Angeles.

Araújo, M.B., Whittaker, R.J., Ladle, R.J., Erhard, M., 2005. Reducing uncertainty in projections of extinction risk from climate change. Glob. Ecol. Biogeogr. 14, 529-538.

Baillie, J.E.M., Collen, B., Amin, R., Akçakaya, H.R., Butchart, S.H.M., Brummitt, N., Meagher, T.R., Ram, M., Hilton-Taylor, C., Mace, G.M., 2008. Toward monitoring global biodiversity. Conserv. Lett. 1, 18-26.

Bergman, K.O., Kindvall, O., 2004. Population viability analysis of the butterfly Lopinga achine in a changing landscape in Sweden. Ecography 27, 49-58.

Borges, P.A.V., Aguiar, C., Amaral, J., Amorim, I.R., André, G., Arraiol, A., Baz, A., Dinis, F., Enghoff, H., Gaspar, C., Ilharco, F., Mahnert, V., Melo, C., Pereira, F., Quartau, J.A., Ribeiro, S., Ribes, J., Serrano, A.R.M., Sousa, A.B., Strassen, R.Z., Vieira, L., Vieira, V., Vitorino, A., Wunderlich, J., 2005. Ranking protected areas in the Azores using standardized sampling of soil epigean arthropods. Biodivers. Conserv. 14, 2029-2060.

Borges, P.A.V., Lobo, J.M., Azevedo, E.B., Gaspar, C., Melo, C., Nunes, L.V., 2006. Invasibility and species richness of island endemic arthropods: a general model of endemic vs. exotic species. J. Biogeogr. 33, 169-187.

Borges, P.A.V., Oromí, P., Serrano, A.R.M., Amorim, I.R., Pereira, F., 2007. Biodiversity patterns of cavernicolous ground-beetles and their conservation status in the Azores, with the description of a new species: Trechus isabelae n. sp. (Coleoptera, Carabidae, Trechinae). Zootaxa 1478, 21-31.

Borges, P.A.V., Gabriel, R., Arroz, A., Costa, A., Cunha, R., Silva, L., Mendonça, E., Martins, A.F., Reis, F., Cardoso, P., 2010. The Azorean Biodiversity Portal: an internet database for regional biodiversity outreach. Syst. Biodivers. 8, 423-434. Cabeza, M., Arponen, A., Van Teeffelen, A., 2008. Top predators: hot or not? A call for systematic assessment of biodiversity surrogates. J. Appl. Ecol. 45, 976-980.

Cardoso, P., 2009. Standardization and optimization of arthropod inventories - the case of Iberian spiders. Biodivers. Conserv. 18, 3949-3962.

Cardoso, P., Morano, E., 2010. The Iberian spider checklist (Araneae). Zootaxa 2495, $1-52$.

Cardoso, P., Scharff, N., 2009. First record of the spider family Symphytognathidae in Europe and description of Anapistula ataecina sp. n. (Araneae). Zootaxa 2246, 45-57.

Cardoso, P., Borges, P.A.V., Gaspar, C., 2007. Biotic integrity of the arthropod communities in the natural forests of Azores. Biodivers. Conserv. 16, 2883-2901.

Cardoso, P., Aranda, S.C., Lobo, J.M., Dinis, F., Gaspar, C., Borges, P.A.V., 2009. A spatial scale assessment of habitat effects on arthropod communities of an oceanic island. Acta Oecol. 35, 590-597.

Cardoso, P., Arnedo, M.A., Triantis, K.A., Borges, P.A.V., 2010. Drivers of diversity in Macaronesian spiders and the role of species extinctions. J. Biogeogr. 37, 10341046.

Cardoso, P., Erwin, T.L., Borges, P.A.V., New, T.R., in press. The seven impediments in invertebrate conservation and how to overcome them. Biol. Conserv. doi:10.1016/j.biocon.2011.07.024.

Clark, J.A., May, R.M., 2002. Taxonomic bias in conservation research. Science 297, 191-192.

Clausnitzer, V., Kalkman, V.J., Ram, M., Collen, B., Baillie, J.E.M., Bedjanic, M., Darwall, W.R.T., Dijkstra, K.B., Dow, R., Hawking, J., Karube, H., Malikova, E., Paulson, D., Schütte, K., Suhling, F., Villanuevam, R.J., Ellenrieder, N., Wilson, K., 2009. Odonata enter the biodiversity crisis debate: the first global assessment of an insect group. Biol. Conserv. 142, 1864-1869.

Colyvan, M., Burgman, M.A., Todd, C.R., Akçakaya, H.R., Boek, C., 1999. The treatment of uncertainty and the structure of the IUCN threatened species categories. Biol. Conserv. 89, 245-249.

Cumberlidge, N., Ng, P.K., Yeo, D.C.J., Magalhaes, C., Campos, M.R., Alvarez, F., Naruse, T., Daniel, S.R., Esser, L.J., Attipoe, F.Y.K., Clotilde-Ba, F.-L., Darwall, W., Mcivor, A., Ram, M., Baillie, J.E.M., Collen, B., 2009. Freshwater crabs and the biodiversity crisis: importance, threats, status, and conservation challenges. Biol. Conserv. 142, 1665-1673.

Dunn, R.R., 2005. Modern insect extinctions, the neglected majority. Conserv. Biol. 19, 1030-1036.

Dunn, R.R., Harris, N.C., Colwell, R.K., Koh, L.P., Sodhi, N.S., 2009. The sixth mass coextinction: are most endangered species parasites and mutualists? Proc. Roy. Soc. B 276, 3037-3045.

Elith, J., Graham, C.H., Anderson, R.P., Dudik, M., Ferrier, S., Guisan, A., Hijmans, R.J., Huettmann, F., Leathwick, J.R., Lehmann, A., Li, J., Lohmann, L.G., Loiselle, B.A., Manion, G., Moritz, G., Nakamura, M., Nakazawa, Y., McC Overton, J., Peterson, A.T., Phillips, S.J., Richardson, K., Scachetti-Pereira, R., Schapire, R.E., Soberon, J., Williams, S., Wisz, M.S., Zimmermann, N.E., 2006. Novel methods improve prediction of species' distributions from occurrence data. Ecography 29, 129-151.

Fox, R., Warren, M.S., Brereton, T.M., Roy, D.B., Robinson, A., in press. A new Red List of British butterflies. Insect Conserv. Diver. doi:10.1111/j.1752-4598.2010.00117.x. 
Gärdenfors, U., Hilton-Taylor, C., Mace, G.M., Rodríguez, J.P., 2001. The application of IUCN Red List criteria at regional levels. Conserv. Biol. 15, 1206-1212.

Gaspar, C., Borges, P.A.V., Gaston, K.J., 2008. Diversity and distribution of arthropods in native forests of the Azores archipelago. Arquipélago 25, 1-30.

Gaspar, C., Gaston, K.J., Borges, P.A.V., Cardoso, P., in press. Selection of priority areas for arthropod conservation in the Azores archipelago. J. Insect Conserv. doi:10.1007/s10841-010-9365-4.

Gaston, K.J., 1994. Rarity. Chapman and Hall, London.

Gaston, K.J., 2003. The Structure and Dynamics of Geographic Ranges. Oxford University Press, Oxford.

Gaston, K.J., 2010. Valuing common species. Science 327, 154-155.

Gaston, K.J., Rodrigues, A.S.L., 2003. Reserve selection in regions with poor biological data. Conserv. Biol. 17, 188-195.

Hallingbäck, T., 2007. Working with Swedish cryptogam conservation. Biol. Conserv. 135, 334-340.

Hallingbäck, T., Hodgetts, N., Raeymaekers, G., Schumacker, R., Sérgio, C., Søderstrøm, L., Stewart, N., Vana, J., 1998. Guidelines for application of the revised IUCN threat categories to bryophytes. Lindbergia 23, 6-12.

IUCN, 2001. IUCN Red List Categories and Criteria version 3.1. <http://www. redlist.org/ technical-documents/categories-and-criteria/2001-categories-criteria (accessed 16.03.11).

IUCN, 2010. IUCN Red List of Threatened Species. Version 2010.4. <http:// www.iucnredlist.org> (accessed 01.04.11).

Koh, L.P., Dunn, R.R., Sodhi, N.S., Colwell, R.K., Proctor, H.C., Smith, V.S., 2004. Species coextinctions and the biodiversity crisis. Science 305, 1632-1634.

Kozlowski, G., 2008. Is the global conservation status assessment of a threatened taxon a utopia? Biodivers. Conserv. 17, 445-448.

Lamoreux, J., Akçakaya, H.R., Bennun, L., Collar, N.J., Boitani, L., Brackett, D., Bräutigam, A., Brooks, T.M., Fonseca, G.A.B., Mittermeier, R.A., 2003. Value of the IUCN Red List. Trends Ecol. Evol. 18, 214-215.

Lewis, O.T., Senior, M.J.M., 2011. Assessing conservation status and trends for the world's butterflies: the Sampled Red List Index approach. J. Insect Conserv. 15, 121-128.

Liu, C., Berry, P.M., Dawson, T.P., Pearson, R.G., 2005. Selecting thresholds of occurrence in the prediction of species distributions. Ecography 28, 385-393.

Lozano, F.D., Saiz, J.C.M., Ollero, H.S., Schartz, M.W., 2007. Effects of dynamic taxonomy on rare species and conservation listing: insights from the Iberian vascular flora. Biodivers. Conserv. 16, 4039-4050.

Mace, G.M., Collar, N.J., Gaston, K.J., Hilton-Taylor, C., Akçakaya, H.R., LeaderWilliams, N., Milner-Gulland, E.J., Stuart, S.N., 2008. Quantification of extinction risk: IUCN's system for classifying threatened species. Conserv. Biol. 22, 1424 1442.

Martín, J.L., 2009. Are the IUCN standard home-range thresholds for species a good indicator to prioritize conservation urgency in small islands? A case study in the Canary Islands (Spain). J. Nat. Conserv. 17, 87-98.

Martín, J.L., Fajardo, S., Cabrera, M.A., Arechavaleta, M., Aguiar, A., Martin, S., Naranjo, M., 2005. Evaluación 2004 de especies amenazadas de Canarias. Especies en peligro de extinción, sensibles a la alteración de su habitat y vulnerables. Consejería de Medio Ambiente y Ordenación Territorial, Gobierno de Canarias, Tenerife.

Martín, J.L., Cardoso, P., Arechavaleta, M., Borges, P.A.V., Faria, B.F., Abreu, C., Aguiar A.F., Carvalho, J.A., Costa, A.C., Cunha, R.T., Fernandes, F.M., Gabriel, R., Jardim, R., Lobo, C., Martins, A.M.F., Oliveira, P., Rodrigues, P., Silva, L., Teixeira, D., Amorim, I.R., Homem, N., Martins, B., Martins, M., Mendonça, E., 2010. Using taxonomically unbiased criteria to prioritize resource allocation for oceanic island species conservation. Biodivers. Conserv. 19, 1659-1682.
Martín-López, B., Montes, C., Ramírez, L., Benayas, J., 2009. What drives policy decision-making related to species conservation? Biol. Conserv. 142, 13701380.

Martín-López, B., González, J.A., Montes, C., 2011. The pitfall-trap of species conservation priority setting. Biodivers. Conserv. 20, 663-682.

Meijer, S.S., Whittaker, R.J., Borges, P.A.V., 2011. The effects of land-use change on arthropod richness and abundance on Santa Maria Island (Azores): unmanaged plantations favour endemic beetles. J. Insect Conserv. 15, 505-522.

Muñoz, J., 2007. Biodiversity conservation including uncharismatic species. Biodivers. Conserv. 16, 2233-2235.

New, T.R., Sands, D.P.A., 2003. The listing and de-listing of invertebrate species for conservation in Australia. J. Insect Conserv. 7, 199-205.

Phillips, S.J., Anderson, R.P., Schapire, R.E., 2006. Maximum entropy modeling of species geographic distributions. Ecol. Model. 190, 231-259.

Pressey, R.L., 2004. Conservation planning and biodiversity: assembling the best data for the job. Conserv. Biol. 18, 1677-1681.

Pysek, P., Richardson, D.M., Pergl, J., Jarosik, V., Sixtova, Z., Weber, E., 2008 Geographical and taxonomic biases in invasion ecology. Trends Ecol. Evol. 23 237-244.

Régnier, C., Fontaine, B., Bouchet, P., 2009. Not knowing, not recording, not listing: numerous unnoticed mollusk extinctions. Conserv. Biol. 23, 1214-1221.

Rodrigues, A.S.L., Pilgrim, J.D., Lamoreux, J.F., Hoffmann, M., Brooks, T.M., 2006. The value of the IUCN Red List for conservation. Trends Ecol. Evol. 21, 71-76.

Schultz, C.B., Hammond, P.C., 2003. Using population viability analysis to develop recovery criteria for endangered insects. Conserv. Biol. 17, 1372-1385.

Seddon, P.J., Soorae, P.S., Launay, F., 2005. Taxonomic bias in reintroduction projects. Anim. Conserv. 8, 51-58.

Stork, N.E., Samways, M.J., Eeley, H.A.C., 1996. Inventorying and monitoring biodiversity. Trends Ecol. Evol. 11, 39-40.

Stroot, P., Depiereux, E., 1989. Proposition d'une méthodologie pour etablir des "Listes Rouges" d'invertébrés menacés. Biol. Conserv. 48, 163-179.

Thuiller, W., Lafourcade, B., Engler, R., Araújo, M.B., 2009. BIOMOD - a platform for ensemble forecasting of species distributions. Ecography 32, 369-373.

Tilman, D., May, R.M., Lehman, C.L., Nowak, M.A., 1994. Habitat destruction and the extinction debt. Nature 371, 65-66.

Triantis, K.A., Borges, P.A.V., Ladle, R.J., Hortal, J., Cardoso, P., Gaspar, C., Dinis, F., Mendonça, E., Silveira, L.M.A., Gabriel, R., Melo, C., Santos, A.M.C., Amorim, I.R., Ribeiro, S.P., Serrano, A.R.M., Quartau, J.A., Whittaker, R.J., 2010. Extinction debt on oceanic islands. Ecography 33, 285-294.

Van Swaay, C.A.M., Warren, M.S., 2006. Prime Butterfly Areas of Europe: an initial selection of priority sites for conservation. J. Insect Conserv. 10, 5-11.

Van Swaay, C.A.M., Nowicki, P., Settele, J., Van Strien, A.J., 2008. Butterfly monitoring in Europe: methods, applications and perspectives. Biodivers. Conserv. 17, 3455-3469.

Van Swaay, C.A.M., Cuttelod, A., Collins, S., Maes, D., Munguira, M.L., Sasic, M., Settele, J., Verovnik, R., Verstrael, T., Warren, M.S., Wiemers, M., Wynhoff, I., 2010. European Red List of Butterflies. Publications Office of the European Union, Luxembourg.

Van Swaay, C., Maes, D., Collins, S., Munguira, M.L., Sasic, M., Settele, J., Verovnik, R. Warren, M., Wiemers, M., Wynhoff, I., Cuttelod, A., 2011. Applying IUCN criteria to invertebrates: how red is the Red List of European butterflies? Biol. Conserv. $144,470-478$.

Verdú, J.R., Galante, E., 2006. Libro rojo de los invertebrados de España. Dirección General para la Biodiversidad. Ministerio de Medio Ambiente, Madrid. 